G. E. Dumitran \& L. I. Vuta, Int. J. of Design \& Nature and Ecodynamics. Vol. 9, No. 2 (2014) 129-140

\title{
INVESTIGATIONS ON MANAGEMENT SOLUTIONS FOR GOLESTI RESERVOIR, CONSIDERING THE ECOLOGICAL ASPECTS
}

\author{
G. E. DUMITRAN \& L. I. VUTA \\ Department of Hydraulics, Hydraulic Machinery and Environmental Engineering, \\ University "Politehnica" of Bucharest, Romania.
}

\begin{abstract}
Nowadays many aquatic ecosystems have become more eutrophic, as anthropic pollution causes the acceleration of eutrophication, which is a slow natural process. Therefore, the cultural eutrophication occurs more rapidly and causes problems in the affected water bodies. Since most of the reservoirs have complex use (flood attenuation, generation of hydroelectricity, household and industrial water supply, and irrigation), several models have been already developed to simulate the behavior of eutrophic ecosystems.

The objective of this study was to determine the benefits of sustainable exploitation of an eutrophic lake. Therefore, the study aims, first, to analyze the trophic level in the lake, and second, to identify the best scenario of reservoir exploitation, in order to avoid the occurrence of eutrophic phenomenon or to minimize this effects. Also, based on the experimental data and an ecological model, the lake stratification and thermocline variation, correlated with operating conditions, have been studied.

The study case is represented by a shallow reservoir in Romania, Golesti, which has 55 million $\mathrm{m}^{3}$ volume and a maximum depth of $32 \mathrm{~m}$. Golesti reservoir allows flood control, hydropower generation, water supply (household and industrial), and irrigation. Values of inflow and outflow from January 2008 to October 2009 were available for the studied reservoir.
\end{abstract}

Keywords: Reservoir, eutrophication, ecological model, nutrients, water quality.

\section{INTRODUCTION}

The natural and artificial addition of nutrients to water bodies and their effects mean the eutrophication [1]. Thus, the first stage of eutrophication corresponds to the increase of nutrients concentration in the water mass, and the second stage is manifested by increased biological productivity, resulting in the proliferation and overgrowth of algae and aquatic plants. This process is called, suggestively, 'algal bloom', and it leads to imbalances in the matter and energy flows. The third stage of the eutrophication process is the oxidation of organic matter settled at the bottom of the water body. Decomposition of algae and other aquatic plants increases the oxygen consumption in the hypolimnion. All the available oxygen will be consumed and the anaerobic conditions will appear in the water, leading to the formation and release of hydrogen sulfide, ammonia, manganese, carbon dioxide, etc. The hydrogen sulfide and ammonia prevent nutrient settlement at the bottom of the lake, having direct effects onto nutrients excess in water and assuring self-supporting conditions for the process of eutrophication. In some water body, this phenomenon can be a natural process but mostly is an effect of the anthropic impact. Natural eutrophication is a very slow process, which can take hundreds of years. However, the artificial or cultural eutrophication occurs more rapidly and causes problems such as decrease of dissolved oxygen (DO) concentration, change in taste and odor, and decrease of available storage capacity.

The sources of nutrients responsible for eutrophication are diffuse sources (natural or artificial) that consist of mineral substances from catchment area and point sources (natural or artificial) that are represented by the tributaries or sewage that come into lake ecosystems. The effects of the eutrophication phenomenon are negatively reflected on many directions: water quality, ecosystem structure and functions, and water use. From the biological point of view, direct and indirect effects 
are identifiable. The most important biological effect is the death of fish species that requires high levels of DO, such as trout or salmon. The community composition of the water body changes, the food webs alters, and finally, fish species adapted to low DO, such as carp, will prevail.

The lakes and reservoirs are classified using a set of qualitative descriptors based on measurable quantities such as nutrients concentration, turbidity, DO concentration, and algal biomass. Five trophic classes are set: ultra-oligotrophic, oligotrophic on lake morphometry and definition of advective transport and density gradients. The hydrodynamics of lakes/reservoirs is connected to the motion of a stratified fluid affected by external forces, the instability of these motions, and the dynamics of turbulence in a stratified environment. For these ecosystems, the temperature distribution over time and depth is influenced by heat exchanges between water mass and atmosphere. These heat exchanges, along with the kinetic energy of wind, are the dominant factors that control the thermal regime, namely the dynamic of the analyzed ecosystems. In order to understand the problem of eutrophication, it is necessary to comprehend the thermal structure and hydrodynamics of surface water body [2].

Most lakes in temperate regions are dimictic ecosystems. For this kind of ecosystems, the climate conditions impose a particular dynamics to water masses: two stratification cycles (in summer and winter) and two mixing periods (in spring and autumn). The yearly stratification cycle has important implications for chemical and biological fate and transport in a lake. During stratification, the lake is characterized by an upper layer of more or less uniformly warm, circulating, and sometimes turbulent water called the epilimnion. The thermocline separates the upper warm waters from the colder and denser bottom layer of the lake, the hypolimnion, and is the plane of maximum rate of decrease of temperature with respect to depth [1]. Because of the strong density gradient between the hypolimnion and epilimnion, water does not often circulate between the two layers. As a result, there is very little transport of chemical and biological constituents between the two layers. Since the hypolimnion is not in contact with the surface and little diffusion of dissolved oxygen occurs between layers, the hypolimnion can become devoid of oxygen.

Aquatic ecosystem functioning modeling is done by parameterization of connections with trophic levels, by introducing some state variables that characterize the system. The dynamic of those variables is determined by physical processes like light absorption, turbulence, or advection and by biochemical processes like nutrients assimilation, dissipative processes (respiration, excretion, and mortality), and sedimentation [3].

\section{METHODOLOGY}

The proposed ecological model is divided into a hydrodynamic/thermal [4] and a biochemical model [2]. Since the biochemical model needs large number of simulations, a separation between physical and biochemical model was preferred. Introducing the output data from physical model into a biochemical model did the coupling of the components. For this biochemical model, four state variables are considered: two nutrients - total nitrogen (TN) and total phosphorus (TP), dissolved oxygen (DO), and chlorophyll 'a' (Chl). The physical model considers a stratified lake ecosystem, schematized by two layers with low thermal gradient (epilimnion and hypolimnion) and separated by a barrier (thermocline) of high thermal gradient. Temporal variations of state variables are described by the input and output dynamics of biochemical components by the flow that cross the thermocline. The lake ecosystem is considered to be well mixed from late autumn to early spring; thus, the state variables are equal in both layers.

\subsection{Existing data}

The Golesti Lake is an artificial lake of medium size. It has a 55 million $\mathrm{m}^{3}$ volume and a maximum depth of $32 \mathrm{~m}$. Its use is complex; it allows flood control, hydropower generation, household and 


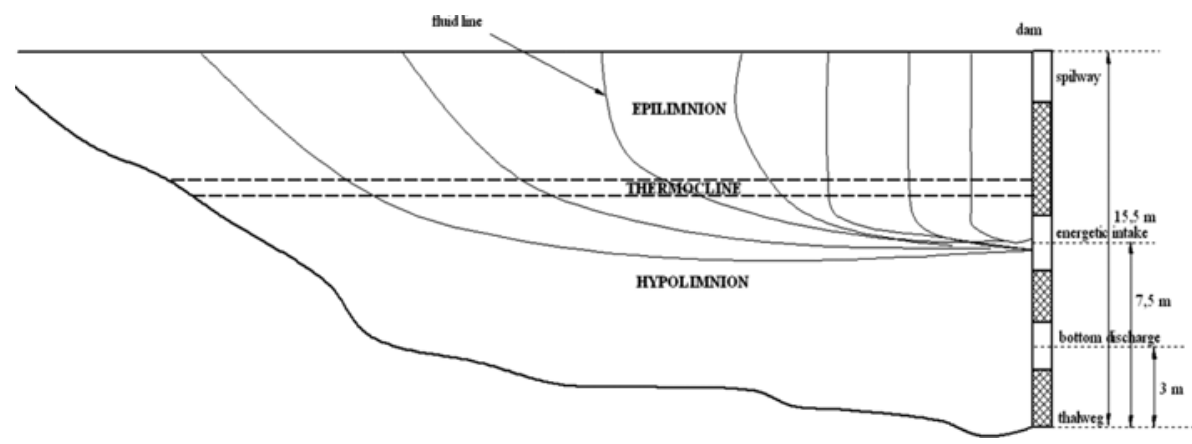

Figure 1: Schematic representation of lake stratification applied to Golesti reservoir.

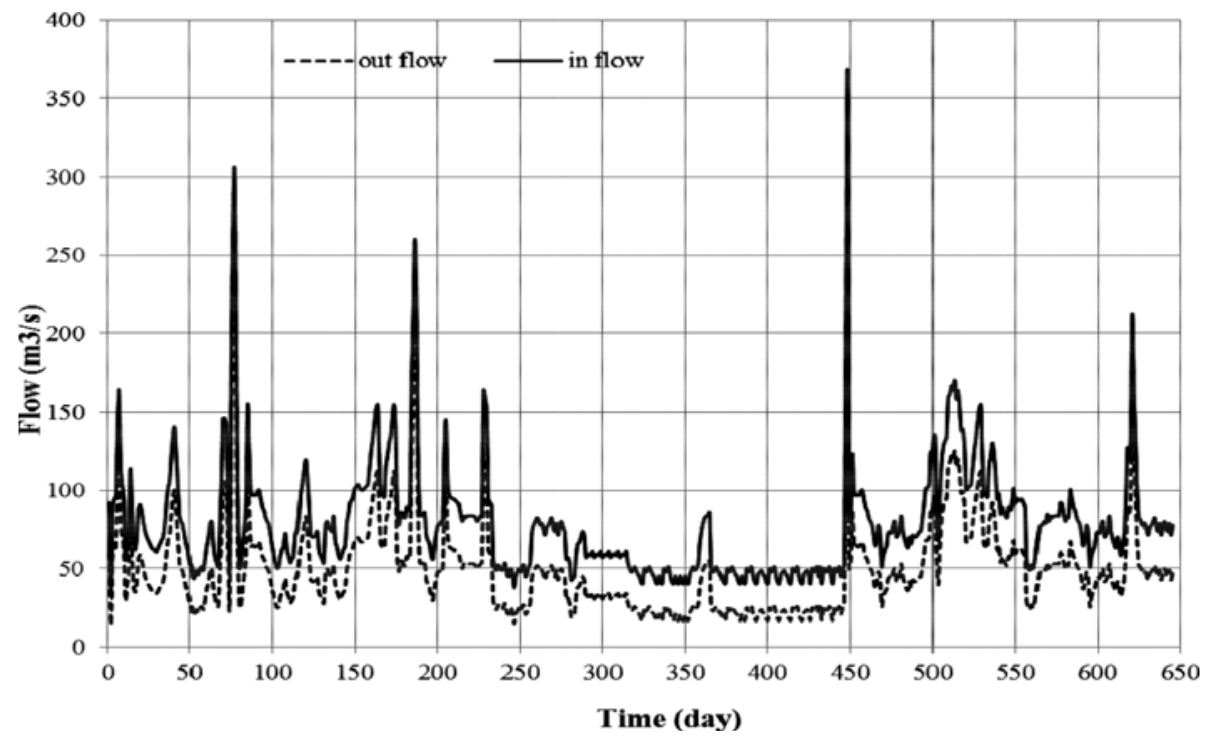

Figure 2: Inflow and outflow values for Golesti reservoir (2008-2009).

industrial water supply, and irrigation. Thus, it prevents downstream flooding for a $50 \mathrm{~km}^{2}$ area, it provides a flow of $156 \mathrm{~m}^{3} /$ day for Bucharest (domestic and industrial) and $9 \mathrm{~m}^{3} / \mathrm{s}$ for irrigation of a $100 \mathrm{~km}^{2}$ area, it is the secondary source for industrial water supply of Pitesti City (up to $6 \mathrm{~m}^{3} / \mathrm{s}$ ), and it is used also for electricity generation, having an installed power of $8 \mathrm{MW}$.

Golesti arrangement includes a dam, the spillways, bottom discharge structures, and the hydropower plant. The energetic intake is placed at $7.5 \mathrm{~m}$ above the thalweg (see Fig. 1) and can transit up to $90 \mathrm{~m}^{3} / \mathrm{s}$. For Golesti reservoir, values of inflow and outflow from January 2008 (day 1) to October 2009 (day 645) were available (see Fig. 2). The first year was a rainy one, and the second year was dry. Also, in both years, extreme flood events were registered. In Golesti reservoir, summer circulation is characterized by thermal stratification, which usually occurs in the late March or early April and lasts until the end of October. Usually, the thermocline layer during the summer stratification establish at 6-7 m depth.

Golesti reservoir is a heavily modified water body, which means that its physical characteristics have been substantially changed due to human activities [5]. Each year, as the lake surface warms 


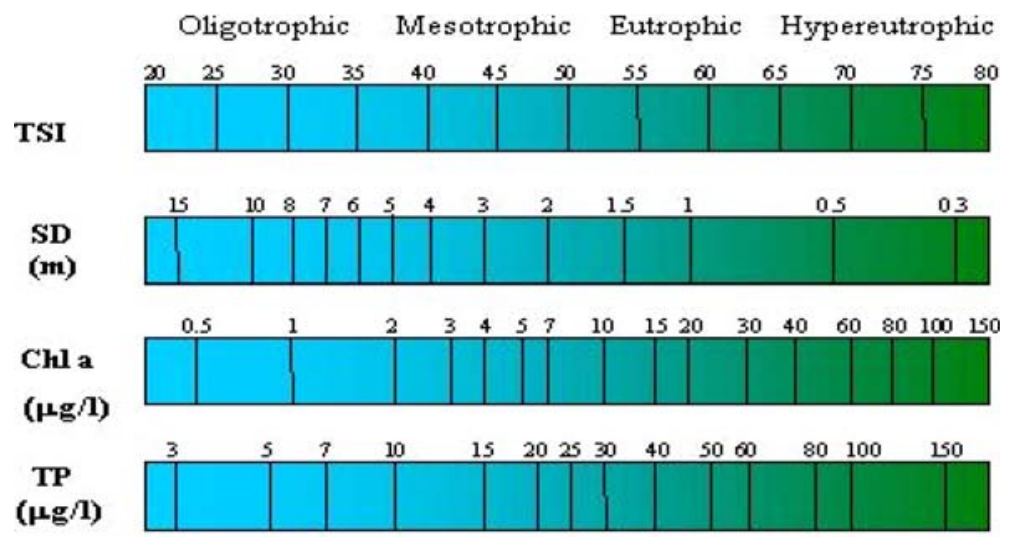

Figure 3: Trophic status index values [6].

through the springtime, a thermocline develops in the lake by early summer. This thermal gradient isolates cold and dense water within the reservoir's lower layer. As the summer progresses, the DO in hypolimnion is consumed, leading to anoxia (no oxygen) by late September. The mean water temperature is between $2^{\circ} \mathrm{C}$ and $23^{\circ} \mathrm{C}$ and the values of DO are between 6.91 and $13.3 \mathrm{mg} / \mathrm{l}$. During the last few years, high concentrations of nutrients (phosphorus, nitrogen) and algal biomass have been occasionally recorded, amplifying the deterioration of water quality and generating an eutrophication tendency of the lake.

For assessing the changes in trophic state of aquatic ecosystems, Carlson [6] proposed the following equations for trophic state index (TSI) assessment, as a function of the above parameters (see Fig. 3):

$$
T S I_{C h l}=10 \cdot\left(6-\frac{2.04-0.69 \cdot \ln (C h l)}{\ln 2}\right) ; T S I_{S D}=10 \cdot\left(6-\frac{\ln (S D)}{\ln 2}\right) ; T S I_{T P}=10 \cdot\left(6-\frac{\ln \left(\frac{48}{T P}\right)}{\ln 2}\right) ;
$$

where SD is Secchi depth.

For a good correlation between parameters and the regression model, Carlson recommends to use only the summer values of the parameters. The trophic status index (TSI > 50) obtained for Golesti reservoir shows that the lake was in eutrophic status throughout 2008-2009 (see Fig. 4). There were also some exceptions: phosphorus values in early summer 2008 placed the lake in the hypertrophic category and the nitrogen and chlorophyll content for a short period in 2009 placed it into the mesotrophic category [5].

\subsection{Reservoir management}

Water resources of Romania consist of surface water (rivers and lakes), 93.28\%, and groundwater, $6.72 \%$. In surface water, a very important part corresponds to Danube contribution, which represents $68.00 \%$. Theoretical Romanian water resources were estimated in 2011 to be $134 \mathrm{~km}^{3}$, and the degree of development of river basin is $39.27 \mathrm{~km}^{3}$ [7]. Taking into account only the inland rivers contribution, Romania has relatively low water resources [8]. Most of reservoirs in Romania are used for drinking water supply. However, the leading role in both the strategy and tactics of the reservoirs water management is the energy production, while the communal water supply and rec- 


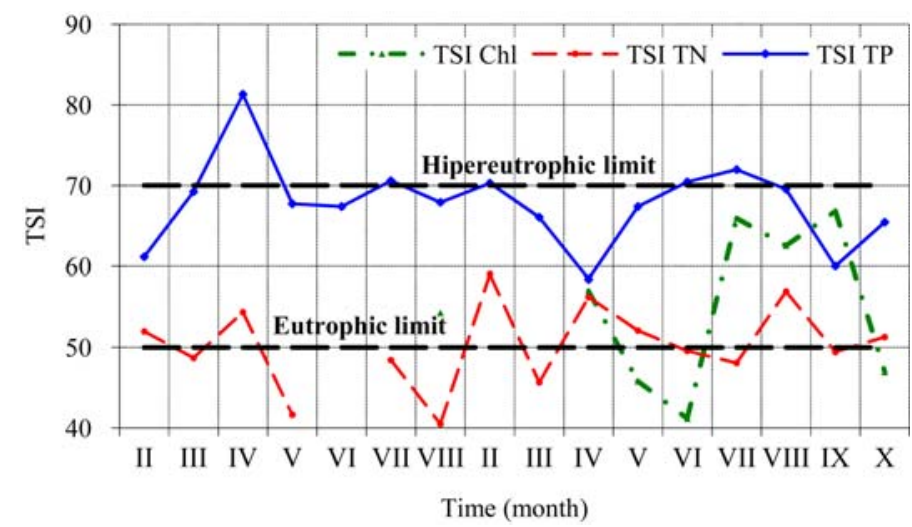

Figure 4: Trophic status index values for Golesti reservoir [2].

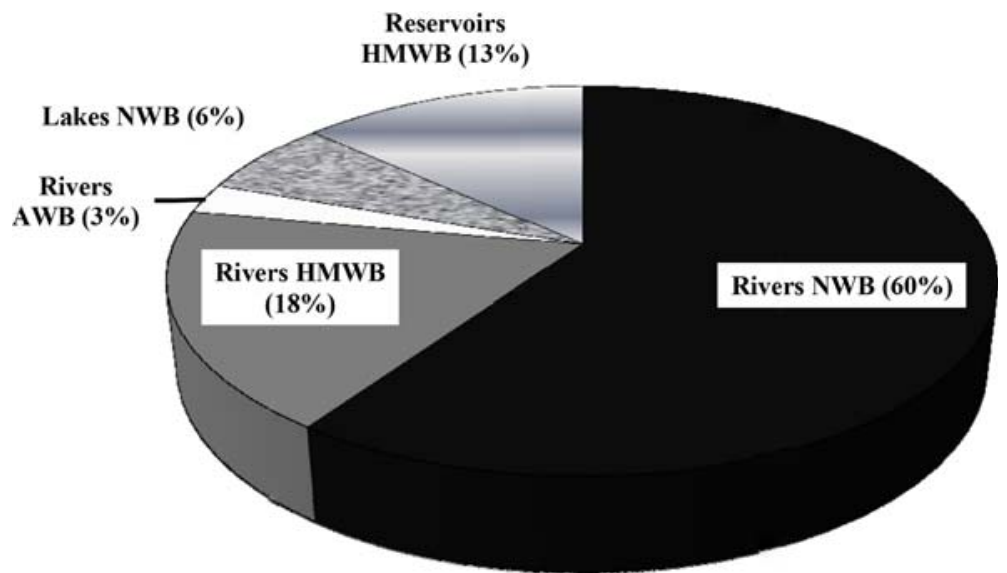

Figure 5: The nature of water body in Romania (NWB = natural water body; AWB = artificial water body; HMWB = heavily modified water body).

reation are just complementary uses of water resources. For these reasons, conservation, water saving and reuse, and not at least water quality are serious problems.

In Romania, the quality of water is monitored according to the structure and the methodological principles of Integrated Monitoring System of Wastewater in Romania (SMIAR), restructured in accordance with the requirements of European Directives. In 2011, the assessment of ecological status/ecological potential at the national level was performed for a total of 798 water bodies that are provided with annual monitoring program. Their distribution is as follows (see Fig. 5):

- 476 natural water bodies ranging from rivers;

- 145 heavily modified water bodies ranging from rivers;

- 51 natural water bodies - natural lakes;

- 106 heavily modified water bodies - lakes and reservoirs;

- 20 artificial water bodies ranging from rivers. 
Environmental objective for surface water bodies is considered to be achieved when the water bodies attain high ecological status or good ecological potential. The quality of the main lakes and reservoirs in Romania reveals that only $7.85 \%$ from lakes have a good ecological status and 50\% from reservoirs have a good ecological potential [2]. Many aquatic ecosystems have become more eutrophic in recent years. Thus, in 2012 Romania reported almost 60\% lakes/reservoirs with eutrophication problems. Many reservoirs in Romania are eutrophic when judging by TP, but based on the concentration of chlorophyll and phytoplankton, they are mesotrophic or even oligotrophic.

All lake protection and restoration activities involve management. The term 'lake management' encompasses a broad array of inter-related topics, disciplines, and applications. It could be management for protection, enhancement, restoration, and/or rehabilitation. Lake management activities must include lake and watershed studies, identification of problems causing various lake symptoms, evaluating options for remediation, planning and implementing that remediation, and performing all types of social, political, scientific, economic, and other actions related to the waterbody [9]. Despite the numerous conflicts of interest in managing multipurpose reservoirs, raw water has to be provided not only at an adequate amount but also of high quality. For instance, for a reservoir used not only for energy production but for drinking water supply as well, a poor water quality will be reflected in higher treatment costs (see Fig. 6).

The study directions for a good management of aquatic ecosystems are:

- applying new instrumentation and techniques for reservoir water quality monitoring;

- implementing in situ control strategies to remove nutrients from the water;

- adopting best practices in the management of cyanobacteria and algae;

- using in-reservoir water quality management strategies (mixing and destratification, hypolimnetic oxygenation, flocculants and nutrient binding agents, and biomanipulation);

- employing hydrodynamic and water quality models to facilitate understanding the ecosystems

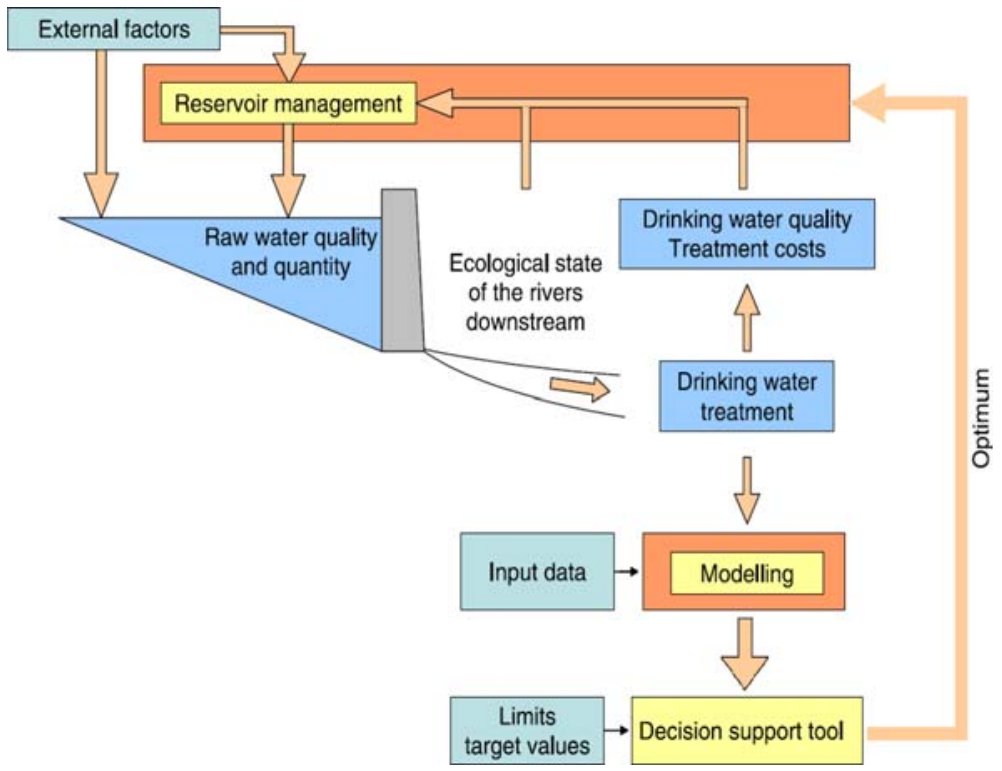

Figure 6: Scheme of approach to develop a decision-making tool to optimize reservoir management and consequently drinking water treatment [10]. 
behavior;

- actively integrating reservoir management and water treatment.

Khrisanov and Osipov have suggested three levels of environmental management for limiting the inputs of organic and mineral nutrients from non-point sources [11]. The first level envisages environmentally clean agricultural technologies. The second level actions are oriented toward reduction of the water consumption and hence reduction in migration of nutrients to aquatic ecosystems. The third action level envisages reduction of the nutrient concentrations directly into water bodies by means of phytoremediation, the macrophyte actively absorbing dissolved nutrients.

\section{RESULTS}

In this study, the transit of flow from lake to downstream of the dam is investigated. This transit is expected to have positive effects on water quality, resulting in lake destratification. The water is discharged by spillways, energetic water intake, and bottom discharge structures. Thus, the maximum flow over the spillway is $6.175 \mathrm{~m}^{3} / \mathrm{s}$, while the value for the energetic water intake is of $90 \mathrm{~m}^{3} / \mathrm{s}$. Also, $12.240 \mathrm{~m}^{3} / \mathrm{s}$ can be transited by the bottom discharge structures.

The spillway discharge does not influence at all the reservoir thermocline, even at maximum flow. Thus, the depth of disturbed water layer due to the flow by energetic intake and bottom discharge are analyzed. Also the possibilities of thermocline erosion have been assessed. Considering a constant daily discharge and knowing the variation of water temperature/density with depth, the withdrawal layer structure was investigated [12]. First, the Brunt-Vaisala frequency is computed by:

$$
N_{0}=\sqrt{\frac{g}{\rho_{0}}\left(\frac{d \rho}{d z}\right)},
$$

where $g$ is the gravitational acceleration, $\rho_{0}$ is the water density at the surface $\left(\mathrm{kg} / \mathrm{m}^{3}\right)$, and $d \rho / d z$ is the vertical density gradient.

The withdrawal layer structure is determined by the value of internal Froude and Grashof numbers, which are given by:

$$
F r_{i}=\frac{Q_{w}}{N_{0} \cdot L^{2}}, G r=\frac{N_{0}^{2} \cdot L^{4}}{\varepsilon_{v}^{2}}
$$

where $Q_{w}\left(\mathrm{~m}^{2} / \mathrm{s}\right)$ is the discharge per unit width, $L(\mathrm{~m})$ is the reservoir length, and $\varepsilon_{v}\left(\mathrm{~m}^{2} / \mathrm{s}\right)$ is the average vertical eddy diffusivity. Thus, the thickness of perturbed water layer is computed (see Fig. 7). For the energetic intake, the thickness of the perturbed layer was of $2.8 \mathrm{~m}$, while for the bottom discharge, the thickness was $4.4 \mathrm{~m}$.

Further, we investigated several exploitation scenarios in order to identify the one with best results in preventing the development of eutrophication or to minimize its effects. Since the most unfavorable situations regarding the water quality and eutrophication phenomenon appear during the warm period, five possible scenarios for reservoir exploitation were investigated for this period. The scenarios are:

- S1: Real situation - daily use of water for energy production combined with spillway discharge; the bottom discharge is used only in extreme flood events.

- S2: daily use of water for energy production combined with spillway discharge; the bottom discharge is not used at all.

- S3: daily use of water for energy production, spillway discharge, and use of bottom discharge with 


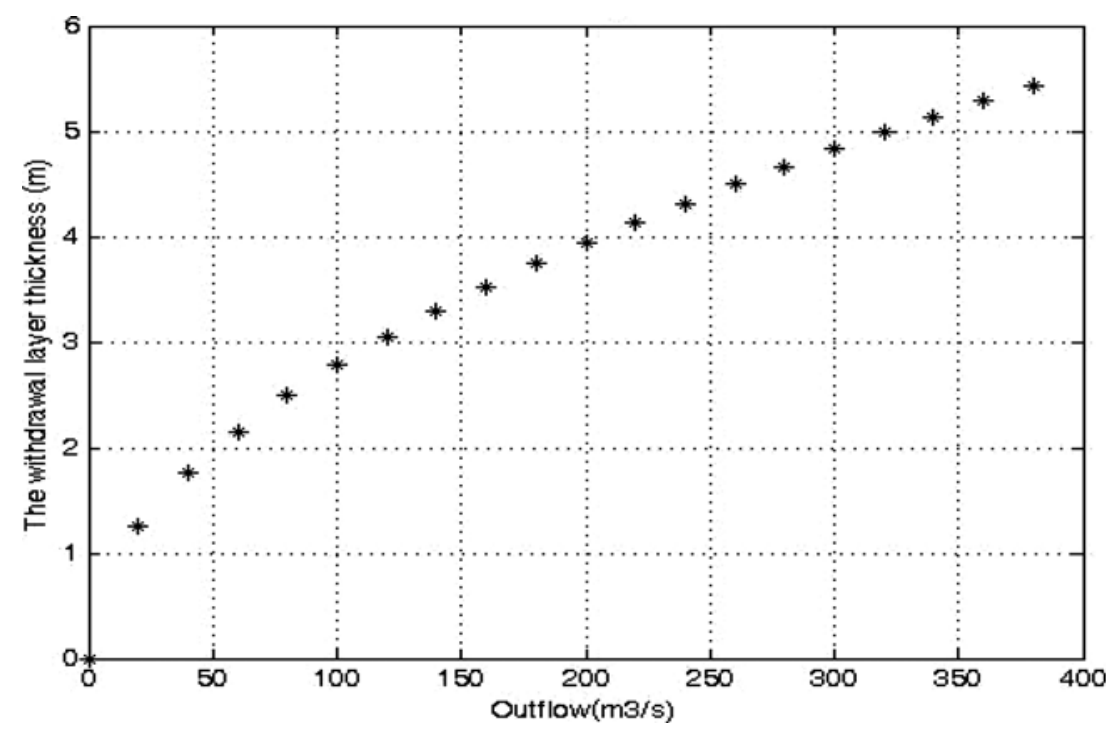

Figure 7: The dependence between thickness of perturbed water layer and outflow.

variable flow, ranging from 1 to $3 \mathrm{~m}^{3} / \mathrm{s}$, for half of the energetic water intake period of use.

- S4: daily use of water for energy production, spillway discharge, and use of bottom discharge once at 2 weeks, at a constant flow of $20 \mathrm{~m}^{3} / \mathrm{s}$, half of the time of the energetic water intake period of use; - S5: daily use of water for energy production, spillway discharge, and use of bottom discharge once per week, half of the time of the energetic water intake period of use, at a constant flow of $10 \mathrm{~m}^{3} / \mathrm{s}$.

Using the ecological model, simulations of lake's behavior have been done for the five exploitation scenarios. Thus, the evolution tendency for the eutrophication indicators (DO, TP, TN and Chl) was analyzed and the optimal scenario with regard to eutrophication effects has been identified.

The first indicator that was investigated is DO. Dissolved oxygen and temperature are two of the fundamental variables in lake/reservoir. Since water temperature directly influences aquatic organisms, it regulates dissolved oxygen concentrations within a lake. Dissolved oxygen saturation is a basic parameter used in a great many water quality model since the degree of DO depletion at the bottom of the lake can be an indicator of its trophic state. Warm water holds less oxygen than cold water; thermal stratification causes extreme DO conditions within waterbodies. Since there is no replenishment of oxygen to the bottom of the lake, the oxygen may gradually become depleted by decomposers that live at this level. If DO concentration drops below $2 \mathrm{mg} / \mathrm{l}$, fish kills may occur and if it becomes less than $1 \mathrm{mg} / \mathrm{l}$, nutrients, once bound to bottom sediments, are released into the water through a chemical reaction. When stratification breaks down in autumn, algae are able to utilize these nutrients, and as a result, algal bloom may occur. Here for DO saturation, the following polynomial equation developed by Baca and Arnett was used [13]:

$$
D O_{\text {sat }}=14.652-(0.41022 \cdot T)+\left(0.007991 \cdot T^{2}\right)-\left(0.000077774 \cdot T^{3}\right)
$$




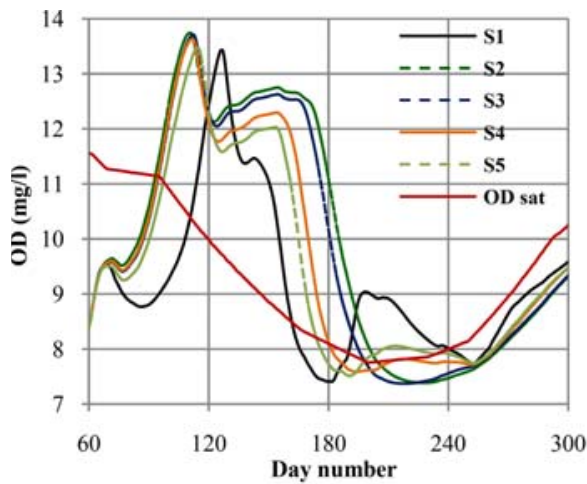

(a)

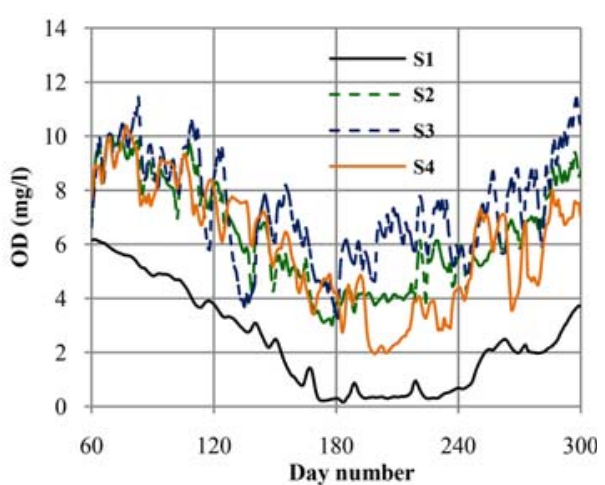

(b)

Figure 8: The DO evolution in time for epilimnion layer (A) and hypolimnion layer (B) in Golesti reservoir.

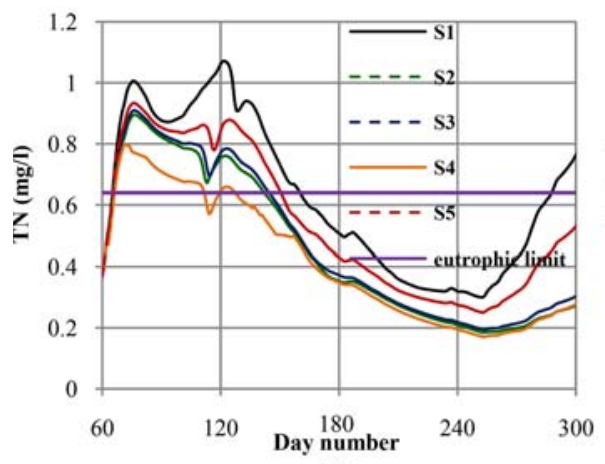

(a)

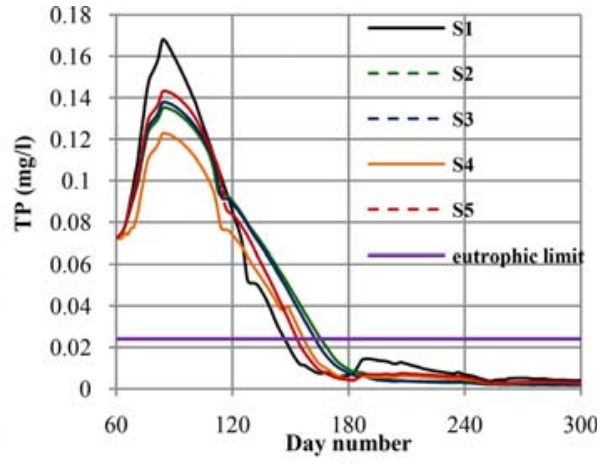

(b)

Figure 9: The nutrients evolution in time: TN (A) and TP (B) in Golesti reservoir.

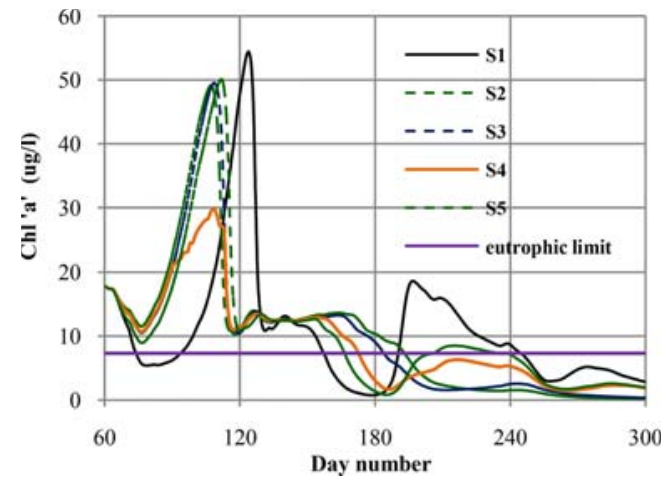

Figure 10: The chlorophyll 'a' evolution in time in Golesti water mass. 
In Fig. 8, DO evolution in epilimnion and hypolimnion is presented. Regarding the two nutrients mainly responsible for eutrophication occurrence, phosphorus and nitrogen, their variation over time is presented in Fig. 9, and Fig. 10 presents the Chl variation. It can be remarked that during the algal bloom, although TP and TN concentrations have a decreasing tendency, the values are much higher than mesotrophic limits. The generally accepted threshold for a eutrophic lake is $0.025 \mathrm{mg} / \mathrm{l}$ for TP and $0.650 \mathrm{mg} / \mathrm{l}$ for TN [14]. For Golesti reservoir, the maximum values are $0.17 \mathrm{mg} / \mathrm{l}$ for TP and $1.10 \mathrm{mg} / \mathrm{l}$ for TN. Regarding the algal biomass, as almost all lakes in temperate areas, two blooming periods are registered: one at the beginning of the spring and the other in the early autumn. The peak values for algal biomass at the beginning of the spring and in the early autumn are $55 \mu \mathrm{g} / \mathrm{l}$ and $18 \mu \mathrm{g} / \mathrm{l}$, respectively.

\section{DISCUSSION}

For the first scenario, we can note that if DO concentration in epilimnion does not reveal any water quality issues. For all the remaining scenarios, an increase in DO in the epilimnion before the first algal bloom is obtained (see Fig. 8). In deep layers, a DO reducing tendency occurs, with negative effects on the aquatic life. However, comparing to S1, for all other scenarios an increase of DO in hypolimnion is noticed, leading to a major improvement in water quality. This is due to a better vertical movement of water generated by occasionally use of bottom discharge structures.

Regarding the nutrients and algal biomass, it is desirable to not exceed the limits of eutrophic ecosystems (see Figs 9 and 10). From this point of view, we can note a decreasing tendency in nutrients concentration from S1 to S4, ranging from $20 \%$ to $45 \%$ for TN and from 5\% and 30\% for TP. Also, for S4, the lake exceeds the eutrophic limit with respect to TN for the shortest period of time, approximately 45 days, while for the rest of the scenarios; this period varies between 70 and 120 days.

Analyzing the nutrients and chlorophyll 'a' variation (see Fig. 10), we can state that the optimal exploitation scenario is the fourth one (S4). In this case, the algal biomass decreases almost by half compared to the other scenarios. Also, this type of management limits the algal biomass for the second bloom period, so that it does not exceed the eutrophication limit of $9 \mu \mathrm{g} / \mathrm{l}$ [15].

For a better comparison between the real situation and optimal scenario, the DO evolution and the TSI were analyzed (see Fig. 11). Therefore, an improvement of reservoir's water quality is observed,

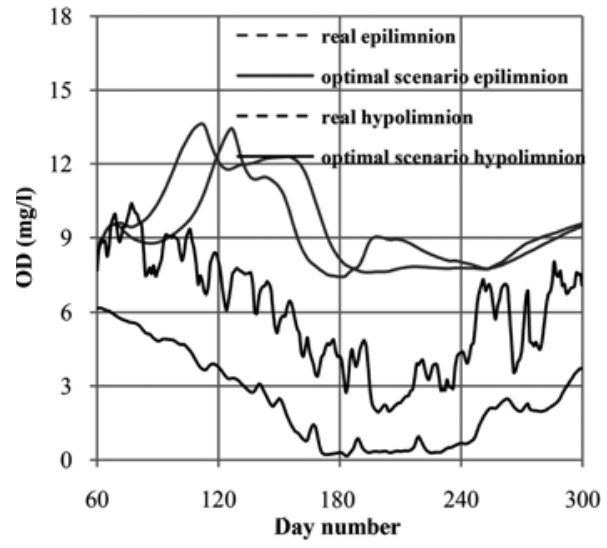

(a)

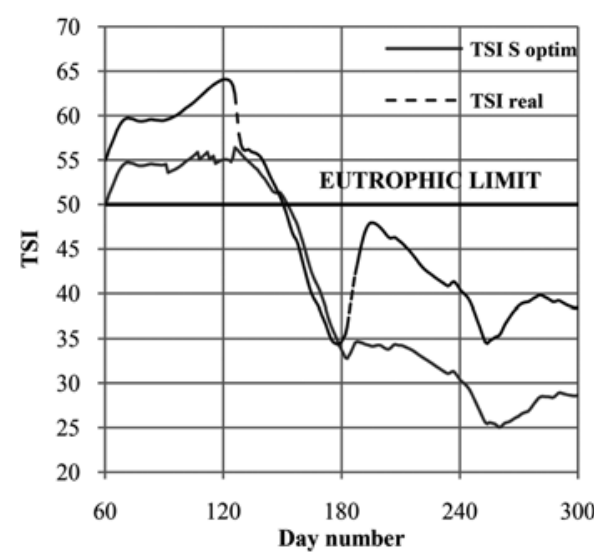

(b)

Figure 11: The DO evolution (A) and TSI (B) in time for real situation and optimal scenario for Golesti reservoir. 
but still not sufficient since the reservoir experiences eutrophication problems since April-May. Observing TSI evolution for S4, Golesti reservoir does not reach the hypertrophic limit. Also, the lake is in the oligotrophic state (TSI < 40) for half of the direct stratification period. Regarding the DO regime, the results reveal a lower probability for anaerobic conditions to occur.

\section{CONCLUSIONS}

The quality of the water stored in a reservoir improves with time as algae and aquatic plants use nutrients and as algae and suspended sediment are deposited. The bottom withdrawal spillway discharges most of the muddy inflow, which decreases the sedimentation rate and increases the useful life of a water reservoir. The water discharged will have a higher sediment and nutrient content than water from conventional surface-withdrawal spillways. The continual bottom-water discharge will promote increased oxygen concentrations and improvement of water quality in water mass.

If the lake is used for energy production, the bottom discharges are used only in extreme situation, in order not to lose energy. In this study, we have tried to identify the optimal solution for reservoirs management to achieve a maximum energetic efficiency but considering the water quality aspects also. Thus, we analyzed the easiest method for eutrophic reservoirs rehabilitation, without using supplementary equipment that implies additional costs. In this sense, we investigated the best possibilities of water transit from upstream to downstream, while preserving a reasonable quality of water in the reservoir.

High concentrations of dissolved nutrients occurred in the bottom water during part of the year, and consequently, the hypolimnetic discharge resulted in an increased removal of these substances from the reservoir. Some of the nutrients are released before being assimilated by the biologic system of the reservoir. So, comparing to surface (epilimnion) discharge, if a large quantity of water is removed from the hypolimnion, an important percent of nutrients will be also removed.

In conclusion, for an optimal reservoir operation, both energetically and environmentally, we recommend a frequent use of the bottom discharge. Thus, we propose an exploitation plan (see Fig. 12) that imposes the use of the bottom discharge every 2 weeks (at least 1 hour, $20 \mathrm{~m}^{3} / \mathrm{s}$ ) and

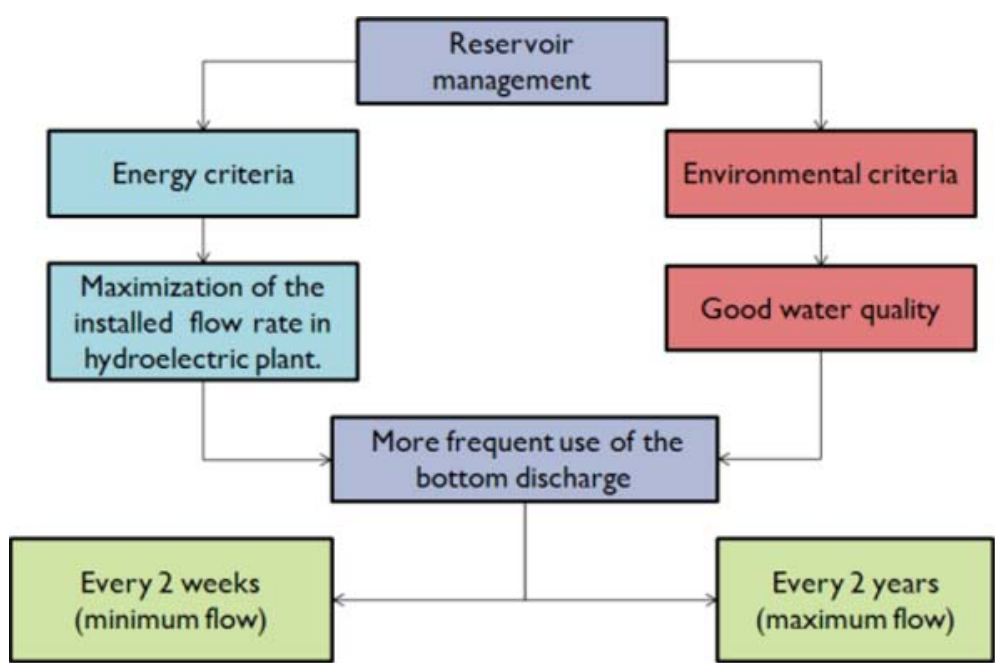

Figure 12: Management plan for Golesti reservoir. 
at least once every 2 years (at least 1 hour at maximum flow, in order to flush sediments and to avoid reservoir clogging).

Obviously our research is not completed and numerous exploitation scenarios remain to be investigated. It is still a good start for assuring a sustainable use of reservoirs that would greatly reduce the future costs of restoring eutrophic lakes.

\section{REFERENCES}

[1] Wetzel, R.G., Limnology: Lake and River Ecosystems, 3rd edn, Academic: London, San Diego, California, 2001.

[2] Dumitran, G.E., Vuţă, L. \& Damian, R., Eutrophication modelling of Golesti reservoir in Romania. Environmental Engineering and Management Journal, 11(2), pp. 1821-1829, 2012.

[3] Chapra, S.C., Surface Water - Quality Modeling, McGraw-Hill: New York, 1997.

[4] Dumitran, G.E. \& Vuţă, L., Estimation by simulating the net transfer rate into aquatic ecosystems. Proceedings of the 18th European Concurrent Engineering Conference \& 8th Future business Technology Concerence, Bucharest, Romania, 18-20 April, pp. 63-65, 2012.

[5] Imberger, J. \& Hamblin, P.F., Dynamics of lakes, reservoirs and cooling ponds. Annual Review of Fluid Mechanics, 14, pp. 153-164, 1982. doi: http://dx.doi.org/10.1146/annurev. fl.14.010182.001101

[6] Carlson, R.E., A trophic state index for lakes. Limnology and Oceanography, 22, pp. 361-369, 1977. doi: http://dx.doi.org/10.4319/1o.1977.22.2.0361

[7] http://www.anpm.ro/ Mediu/rapoarte (accessed 2012).

[8] Oroian, I. \& Odagiu, A., Evolution of water quality in Romania. Studies on Water Management Issues, ed Dr. Muthukrishnavellaisamy Kumarasamy, InTech: Croatia, 2012.

[9] Planning and management of lakes and reservoirs: an integrated approach to eutrophication a training module, UNEP-IETC, UNEP International Environmental Technology Centre, Osaka/ Shiga, 2000.

[10] Slavik, I. \& Uhl. W., Analysing water quality changes due to reservoir management and climate change for optimization of drinking water treatment. Water Science \& Technology: Water Supply-WSTWS, 9(1), pp. 99-105, 2009.

[11] Khrisanov, N.I. \& Osipov, G.K., Reservoir Eutrophication Regulation (Gidrometeoizdat, St. Petersburg), 1993.

[12] Fischer, H., List, E., Koh, R., Imberger, J. \& Brooks, N., Mixing in Inland and Coastal Waters, Academic Press Inc: New York, 1979.

[13] Bowie, G.L., Mills, W.B., Porcella, D.B., Campbell, C.L. et al., Rates, constants, and kinetics formulation in surface water quality modeling, EPA 600/3-85/040, 1985.

[14] Addy, K. \& Green, L., Dissolved oxygen and temperature. Natural Resources Facts, Fact Sheet No. 96-3, 1997, Fact Sheet No. 96-4.

[15] Nurnberg, G.K., Trophic state of clean and colored, soft- and hardwater lakes with special consideration of nutrients, anoxia, phytoplankton and fish. Lake and Reservoir Management, 12, pp. 432-447, 1996. doi: http://dx.doi.org/10.1080/07438149609354283 